Media Farmasi p.issn 0216-2083 e.issn 2622-0962 Vol. XV No. 2, Oktober 2019,

\title{
FORMULASI SABUN CAIR EKSTRAK DAUN KECOMBRANG SEBAGAI ANTIKEPUTIHAN
}

\author{
Formulation And Activity Of Anti-Vaginal Discharge Of Kecombrang Leaf Extract Liquid Soap
}

\author{
St. Ratnah, Alfrida Monica Salasa* \\ Jurusan Farmasi Poltekkes Kemenkes Makassar \\ *Email : alfrida.monica@poltekkes-mks.ac.id
}

DOI: https://doi.org/10.32382/mf.v15i2.1125

\section{ABSTRACT}

Etlingera elatior contains chemical compounds that prevent and treat leucorrhoea. However, they are used conventionally, and therefore, they are less effective and efficient. The purpose of this study was to formulate the liquid soap extract of Kecombrang Leaf (Etlingera elatior) and determine the stability of its physical quality and activity as an anti-vaginal discharge. The study uses dried simplicia of Kecombrang leaves extracted by the maceration method with ethanol 96\%. It was formulated into liquid soap with a concentration variation of $6.25 \%$ and $8.75 \%$. Each formula was evaluated for physical quality, microorganism contamination, and activity tests before and after the storage are accelerated. The results obtained by Etlingera Folium extract could be formulated into liquid soap with a concentration of $6.25 \%$ and $8.75 \%$. The stability test results are accelerated, and each concentration meets the requirements of the organoleptic, foam resistance, and pH tests. Microorganism contamination test results also meet the needs of SNI \& BPOM and have anti-vaginal discharge activity. The liquid soap preparation of $8.75 \%$ has an activity greater than the concentration of $6.25 \%$.

Keywords: Candida albicans, Kecombrang leaves, Physical quality, Liquid soap

\begin{abstract}
ABSTRAK
Etlingera elatior mengandung senyawa kimia yang terbukti berfungsi mencegah dan mengobati penyakit keputihan tetapi penggunaannya masih secara tradisional sehingga kurang efektif dan efisien digunakan. Tujuan penelitian adalah untuk memformulasi sediaan sabun cair ekstrak Daun Kecombrang (Etlingera elatior), mengetahui kestabilan mutu fisik dan aktivitas sebagai anti keputihan. Penelitian ini menggunakan simplisia kering Daun Kecombrang yang diekstraksi dengan metode maserasi dengan etanol $96 \%$, diformulasi menjadi sabun cair dengan variasi konsentrasi 6,25\% dan 8,75\%. Masing-masing formula kemudian dievaluasi uji mutu fisik, uji cemaran mikroorganisme dan uji aktivitas sebelum dan setelah penyimpanan dipercepat. Hasil yang diperoleh ekstrak Etlingera Folium dapat diformulasi menjadi sabun cair dengan konsentrasi $6,25 \%$ dan $8,75 \%$. Hasil pengujian kestabilan dipercepat, masing-masing konsentrasi memenuhi persyaratan uji organoleptis, uji ketahanan busa dan uji pH. Hasil uji cemaran mikroorganisme juga memenuhi syarat SNI \& BPOM serta memiliki aktivitas sebagai anti keputihan, dimana sediaan sabun cair 8,75\% memiliki aktivitas yang lebih besar dari konsentrasi 6,25\%.
\end{abstract}

Kata Kunci : Candida albicans, Daun Kecombrang, Mutu fisik, Sabun cair

\section{PENDAHULUAN}

Kecombrang merupakan tanaman asli Indonesia yang dapat ditemukan di daerah Luwu, Sulawesi Selatan. Buahnya digunakan sebagai bumbu masak dan obat tradisional.

Habsah et al pada tahun 2005 menyatakan bahwa buah kecombrang dapat digunakan untuk penobatan beberapa penyakit infeksi dan penyakit degenerative seperti kanker dan tumor. Selain itu, kecombrang memiliki aktivitas antibakteri dan antioksidan (Muawanah, A., et al, 2012), dan efek menghilangkan bau badan (Sirait. N., 2008).
Kandungan fitokemikal terdiri dari minyak esensial yang bersifat bioaktif (daun 0,0735\%; bunga $0,0334 \%$; batang $0,0029 \%$ dan rhizome $0,0021 \%$ ) (Jafar dkk, 2007). Menurut Naufalin et al., (2005), ekstrak etanol dan etil asetat bunga kecombrang mengandung zat antibakteri yang bersifat bakteriostatik terhadap Bacillus cereus, $P$. aeroginosa, S. typhimurium, dan Eschericia coli. Penelitian sebelumnya yang dilakukan oleh H. Ismail Ibrahim, dkk (2016) menyatakan bahwa Ekstrak etanol, ekstrak dietil eter, dan ekstrak n-butanol Daun kecombrang dapat 
menghambat pertumbuhan Escherichia coli dan Candida albicans.

Penyakit yang bisa ditimbulkan oleh Candida albicans adalah keputihan. Keputihan adalah keluarnya cairan kental dari vagina yang bisa saja terasa gatal, rasa panas atau perih, kadang berbau, bahkan tidak terjadi gejala yang khas. Kondisi ini terjadi karena tergangggunya keseimbangan flora normal dalam vagina (Baedah Madjid, 2003).

Sabun cair kini di produksi karena lebih praktis, dan memiliki bentuk yang menarik serta dapat digunakan untuk mengobati penyakit yang disebabkan oleh bakteri dan jamur. Formulasi sabun dapat dibuat dari beberapa jenis basis diantaranya jenis surfaktan, natrium lauril sulfat, oleum cocos dan $\mathrm{KOH}$ yang membentuk penyabunan ini berbeda sifatnya dan ada kemungkinan mempengaruhi kemampuan ekstrak dalam menghambat pertumbuhan Candida albicans.

Berdasarkan uraian di atas, maka rumusan masalah penelitian ini adalah : Apakah ekstrak Daun Kecombrang dapat diformulasi menjadi sabun cair yang berefek sebagai anti keputihan? Bagaimana kestabilan mutu fisik dan uji cemaran mikrooganisme dari sediaan sabun cair yang mengandung ekstrak Daun Kecombrang? Apakah sediaan yang dibuat dengan variasi konsentrasi ekstrak memiliki aktivitas sebagai anti keputihan?

Tujuannya yaitu : Untuk memformulasi sediaan sabun cair dari ekstrak Daun Kecombrang, mengetahui kestabilan mutu fisik dan cemaran mikroorganimse dari sediaan sabun cair yang mengandung ekstrak Daun Kecombrang dan menentukan aktivitas sediaan sebagai anti keputihan dengan mengukur zona hambat yang terbentuk.

\section{METODE}

\section{Desain, tempat dan waktu}

Jenis penelitian merupakan penelitian eksperimental (penelitian laboratorium). Penelitian ini dilaksanakan bulan Mei -
September Tahun 2018, di Laboratorium Biologi farmasi dan Teknologi Farmasi, Jurusan Farmasi Politeknik Kesehatan Kemenkes RI Makassar.

\section{Alat dan Bahan}

Alat - Alat yang digunakan ; Batang pengaduk, blender, cawan porselin, Erlenmeyer, gelas kimia, gelas ukur, tabung reaksi, cawan petri, climatic chamber, lampu sipritus, lumpang, maserator, thermometer, timbangan, $\mathrm{pH}$ meter, pinset, pipet tetes, sendok tanduk, spatel, sudip, incubator, oven, autoklaf, laminary air flow. Bahan - bahan yaitu ; Etanol $96 \%$, Simplisia Daun Kecombrang (Etlingera elatior). Air suling, carbopol, etanol 96\%, gliserin, metil paraben, natrium lauril sulfat, propilenglikol, pengharum, Pepton Water, Plate Count Agar, Potato Dextrose Agar, Vojel Jhonson Agar, Cetrimid Agar.

\section{Sampel Penelitian}

Sampel penelitian ini adalah Daun kecombrang (Etlingera elatior) yang telah diekstraksi menggunakan metode maserasi yang selanjutnya dibuat formulasi sabun cair.

\section{Prosedur Penelitian \\ Pengambilan Daun Kecombrang}

Daun Kecombrang berupa daun kelima dari pucuk sampai daun yang tidak kuning (sehat), yang diambil pada pagi hari.

\section{Pengolahan Daun Kecombrang}

Daun yang telah dipetik, dibersihkan dan dikeringkan. setelah kering bahan dipotongpotong kecil.

\section{Ekstraksi}

Bahan uji diekstraksi dengan metode maserasi menggunakan pelarut etanol $96 \%$. Ekstrak etanol yang diperoleh dikumpulkan kemudian diuapkan dengan rotavapor dan dikeringkan di atas penangas air.

\section{Rancangan Formula Sabun Cair Ekstrak Daun Kecombrang (Etlingera elatior).}

\begin{tabular}{cccc}
\hline Formula A & \multicolumn{2}{c}{ Formula B } \\
\hline BAHAN & $\%$ & BAHAN & $\%$ \\
\hline $\begin{array}{c}\text { Ekstrak Daun } \\
\text { Kecombrang } \\
\text { (Etlingera elatior) } \\
\text { Natrium lauril } \\
\text { sulfat }\end{array}$ & 6,25 & $\begin{array}{c}\text { Ekstrak Daun } \\
\text { Kecombrang } \\
\text { (Etlingera elatior) }\end{array}$ & 8,75 \\
Gliserin & 1,5 & Natrium lauril & 1,5 \\
& 10 & sulfat & 10 \\
\hline
\end{tabular}




\begin{tabular}{cccc}
\hline Propilenlycol & 10 & Propilenlycol & 10 \\
Metil paraben & 0,3 & Metil paraben & 0,3 \\
Carbopol & 0,25 & Carbopol & 0,25 \\
Pengaroma & q.s & Pengaroma & q.s \\
Aquadest ad. & 100 & Aquadest ad. & 100 \\
\hline
\end{tabular}

\section{Cara Kerja Pembuatan Sabun Cair}

Ditimbang semua bahan yang digunakan. Metil paraben dilarutkan dalam air panas kemudiaan didinginkan. Carbopol ditaburkan diatas larutan metil paraben kemudian di diamkan selama 1 x 24 jam. Setelah1 x 24 jam dihomogenkan. Ditambahkan sebagian gliserin, dan sebagian propilenlycol dalam larutan tersebut. Natrium lauril sulfat dilarutkan kemudian dimasukkan kedalam larutan tersebut di aduk sampai homogen. ekstrak daun kecombrang ditambahkan sisa gliserin, sisa propilenglycol gerus hingga homogen. Lalu ditambahkan basis sabun sampai homogen.

Uji stabilitas sebelum dan sesudah dipercepat dengan metode freeze thaw

Evaluasi mutu fisik sediaan emulgel dilakukan untuk mengetahui kestabilan fisik sabun cair dengan metode stabilitas dipercepat baik sebelum maupun sesudah dilakukan pengujian kemudian dibandingkan hasilnya. Uji ini dilakukan berdasarkan pengaruh stress suhu (freeze thaw) di mana sebagai kontrol ekstrak bahan uji disimpan pada suhu $25^{\circ} \mathrm{C}$ dan untuk siklus freeze thaw sediaan disimpan pada suhu $4^{\circ} \mathrm{C}$ pada 48 jam pertama dan suhu $40^{\circ} \mathrm{C}$ pada 48 jam berikutnya. Siklus freeze thaw terdiri dari satu rentang waktu penyimpanan pada suhu $40^{\circ} \mathrm{C}$ (Chory, et al., 2015).

\section{Evaluasi Sediaan}

\section{Uji Mutu Fisik}

Uji Organoleptis

Uji penampilan dilakukan dengan melihat secara langsung warna, bentuk, dan bau sabun cair yang terbentuk (Depkes RI, 1995).

\section{Uji ketahanan busa}

Daya busa diukur dengan melarutkan sediaan dalam air kemudian dilakukan pengocokan selama 2 menit dan tinggi busa yang terbentuk diukur (Nissa, 2016). Setelah 5 menit busa harus mampu bertahan antara $60-70 \%$ dari volume awal (Dragon et al., 1969).

\section{Uji pH}

Sebelum pengujian alat dikalibrasi menggunakan larutan dapar $\mathrm{pH} 7$ dan $\mathrm{pH} 4.1$ $\mathrm{ml}$ sediaan uji diencerkan dengan aquadest sampai $10 \mathrm{ml}$. elektroda alat dicelupkan ke dalam larutan yang diperiksa, didiamkan beberapa saat hingga jarum $\mathrm{pH}$ meter stabil, $\mathrm{pH}$ yang ditunjukkan jarum $\mathrm{pH}$ meter dicatat (Depkes, 1995).

\section{Uji Cemaran Mikroorganisme}

Uji ALT bakteri dan Uji AKK. Dibuat pengenceran sampel sesuai dengan derajat kontaminasi lalu dihomogenkan. Pengujian Angka Lempeng Total bakteri, dipipet $1 \mathrm{ml}$ dari masing-masing pengenceran sampel, dimasukkan ke dalam cawan yang telah disterilkan. Ditambahkan media PCA, di homogenkan, dibiarkan memadat selanjutnya diinkubasi selama 24 jam pada temperatur $37^{\circ} \mathrm{C}$. Pengujian dilakukan dengan 3 replikasi. Pengamatan dilakukan dengan menghitung jumlah koloni dengan alat colony counter.

Uji Angka Kapang Khamir dilakukan dengan cara, dipipet $1 \mathrm{ml}$ dari masing-masing pengenceran sampel selanjutnya dimasukkan ke dalam plate steril. Ditambahkan media PDA, di homogenkan, dibiarkan memadat selanjutnya diinkubasi pada suhu $25^{\circ} \mathrm{C}$ selama 48 jam. Pengujian dilakukan dengan 3 replikasi. Pengamatan dilakukan dengan menghitung jumlah koloni dengan alat colony counter.

$\begin{array}{ccr}\text { Uji } & \text { identifikasi } & \text { cemaran } \\ \text { Pseudomonas } & \text { aeruginosa } & \text { dan }\end{array}$ Staphylococcus aureus. Dilakukan inokulasi dari masing-masing pengenceran sampel ke media PW, diinkubasi $1 \times 24$ jam dengan suhu $37^{\circ} \mathrm{C}$. Disiapkan media Cetrimide Agar dan Vogel Johnson Agar di dalam cawan petri 
steril, selanjutnya dilakukan inokulasi dari media PW yang paling keruh ke media selektif. Untuk Pseudomonas aeruginosa diinokulasi ke media selektif, sedangkan Staphylococcus aureus diinokulasi ke media VJA. Selanjutnya diinkubasi pada suhu $37^{\circ} \mathrm{C}$ selama 1 x 24 jam. Pengujian dilakukan dengan replikasi sebanyak 3 kali.

\section{Uji Aktivitas}

Paper disk direndam secara bersamaan selama 15 menit pada masingmasing formula. Disiapkan medium SDA, dalam cawan petri Setelah padat, diulas Candida albicans pada permukaan media menggunakan swab steril. Diletakkan Paper disk di atas permukaan medium, selanjutnya diinkubasi pada suhu $25^{\circ} \mathrm{C}$ selama 2 x 24 jam.

\section{Pengumpulan dan Pengolahan Data}

Data yang dikumpulkan berupa hasil evaluasi formulasi sabun cair ekstrak kecombrang sebagai antikeputihan yang meliputi uji organoleptik, cemaran mikroorganisme dan uji aktivitas.

\section{HASIL}

Hasil pengujian yang diperoleh berupa uji stabilitas (uji organoleptik, uji ketahanan busa, uji pH), uji cemaran mikroorganisme (ALT, AKK, dan uji cemaran mikroba patogen) dan uji aktivitas terhadap pertumbuhan Candida albicans. (tabel 1, 2, 3, 4, 5, 6, dan 7).

Tabel 1. Hasil Pengamatan Uji Organoleptik Sabun Cair Ekstrak Daun Kecombrang (Etlingera elatior) sebelum dan sesudah uji stabilitas dipercepat selama 5 siklus menggunakan alat climatic chamber.

\begin{tabular}{|c|c|c|c|c|c|c|c|}
\hline \multirow{3}{*}{ NO } & \multirow{3}{*}{ Formula } & \multicolumn{6}{|c|}{ Organoleptis } \\
\hline & & \multicolumn{3}{|c|}{$\begin{array}{l}\text { Sebelum pengujian } \\
\text { stabilitas dipercepat }\end{array}$} & \multicolumn{3}{|c|}{$\begin{array}{l}\text { Sesudah pengujian } \\
\text { stabilitas dipercepat }\end{array}$} \\
\hline & & Konsistensi & Warna & Bau & Konsistensi & Warna & $\mathrm{Bau}$ \\
\hline \multirow[t]{2}{*}{1.} & Formula 1 & & Hijau & & & Hijau & \\
\hline & (Ekstrak 6,25\%) & Cair & kecoklatan & Khas & Cair & kecoklatan & Khas \\
\hline 2. & $\begin{array}{c}\text { Formula } 2 \text { (Ekstrak } \\
8,75 \%)\end{array}$ & Cair & $\begin{array}{c}\text { Hijau } \\
\text { kecoklatan }\end{array}$ & Khas & Cair & $\begin{array}{c}\text { Hijau } \\
\text { kecoklatan }\end{array}$ & Khas \\
\hline
\end{tabular}

Tabel 2. Hasil Pengamatan Uji Ketahanan Busa Sabun Cair Ekstrak Daun Kecombrang (Etlingera elatior) sebelum dan sesudah uji stabilitas dipercepat selama 5 siklus menggunakan alat climatic chamber.

\begin{tabular}{|c|c|c|c|c|c|c|}
\hline \multirow[b]{3}{*}{ NO } & \multirow[b]{3}{*}{ Formula } & \multicolumn{4}{|c|}{ Tinggi busa yang terbentuk $(\mathrm{cm})$} & \multirow{2}{*}{ Persyaratan } \\
\hline & & \multicolumn{2}{|c|}{ Sebelum pengujian } & \multicolumn{2}{|c|}{ Sesudah pengujian } & \\
\hline & & $\begin{array}{c}\text { Pengocokan } \\
\text { selama } 2 \text { menit }\end{array}$ & $\begin{array}{c}\text { Setelah } \\
\text { didiamkan } \\
\text { selama } 5 \\
\text { menit }\end{array}$ & $\begin{array}{c}\text { Pengocokan } \\
\text { selama } 2 \text { menit }\end{array}$ & $\begin{array}{c}\text { Setelah } \\
\text { didiamkan } \\
\text { selama } 5 \\
\text { menit }\end{array}$ & \multirow{3}{*}{$\begin{array}{c}\text { untuk stabilitas busa } \\
\text { setelah } 5 \text { menit busa } \\
\text { harus mampu } \\
\text { bertahan antara } 60- \\
70 \% \text { dari volume } \\
\text { awal }\end{array}$} \\
\hline 1. & $\begin{array}{c}\text { Formula } 1 \\
(\text { Ekstrak 6,25\%) }\end{array}$ & 6,2 & 5,7 & 3,5 & 3 & \\
\hline 2. & $\begin{array}{c}\text { Formula } 1 \\
(\text { Ekstrak } 8,75 \%)\end{array}$ & 7,8 & 7,4 & 5 & 4 & \\
\hline
\end{tabular}


Tabel 3. Hasil Pengamatan Uji pH Sabun Cair Ekstrak Daun Kecombrang (Etlingera elatior) sebelum dan sesudah uji stabilitas dipercepat selama 5 siklus menggunakan alat climatic chamber.

\begin{tabular}{ccccc}
\hline NO & Formula & $\begin{array}{c}\text { Sebelum pengujian } \\
\text { stabilitas dipercepat }\end{array}$ & $\begin{array}{c}\text { Setelah pengujian } \\
\text { stabilitas dipercepat }\end{array}$ & Persyaratan \\
\hline 1. & $\begin{array}{c}\text { Formula 1 } \\
(\text { Ekstrak 6,25\%) }\end{array}$ & 4,45 & 4,30 & \\
\cline { 1 - 4 } 2. & $\begin{array}{c}\text { Formula 2 (Ekstrak } \\
8,75 \%)\end{array}$ & 4,30 & 4,12 & $3,8-4,5$ \\
\hline
\end{tabular}

Tabel 4. Hasil Pengamatan Uji ALT bakteri Sabun Cair Ekstrak Daun Kecombrang (Etlingera elatior) sebelum dan sesudah uji stabilitas dipercepat selama 5 siklus menggunakan alat climatic chamber.

\begin{tabular}{ccccc}
\hline NO & Formula & $\begin{array}{c}\text { Sebelum pengujian } \\
\text { stabilitas dipercepat }\end{array}$ & $\begin{array}{c}\text { Setelah pengujian } \\
\text { stabilitas dipercepat }\end{array}$ & Persyaratan \\
\hline 1. & $\begin{array}{c}\text { Formula 1 } \\
(\text { Ekstrak 6,25\%) }\end{array}$ & $<10 \mathrm{koloni} / \mathrm{ml}$ & $<10 \mathrm{koloni} / \mathrm{ml}$ & Maksimum 10 \\
koloni $/ \mathrm{ml}$
\end{tabular}

Tabel 5. Hasil Pengamatan Uji AKK Sabun Cair Ekstrak Daun Kecombrang (Etlingera elatior) sebelum dan sesudah uji stabilitas dipercepat selama 5 siklus menggunakan alat climatic chamber.

\begin{tabular}{|c|c|c|c|c|}
\hline $\mathrm{NO}$ & Formula & $\begin{array}{l}\text { Sebelum pengujian } \\
\text { stabilitas dipercepat }\end{array}$ & $\begin{array}{c}\text { Setelah pengujian } \\
\text { stabilitas dipercepat }\end{array}$ & Persyaratan \\
\hline 1. & $\begin{array}{c}\text { Formula 1 } \\
(\text { Ekstrak 6,25\%) }\end{array}$ & $<10$ koloni/ml & $<10$ koloni/ml & \multirow{2}{*}{$\begin{array}{c}\text { Maksimum } 10 \\
\text { koloni/ml }\end{array}$} \\
\hline 2. & $\begin{array}{c}\text { Formula } 2 \text { (Ekstrak } \\
8,75 \%)\end{array}$ & < 10 koloni/ml & $<10$ koloni $/ \mathrm{ml}$ & \\
\hline
\end{tabular}

Tabel 6. Hasil Pengamatan Uji Cemaran Staphylococcus aureus dan Pseudomonas aeruginosa Sabun Cair Ekstrak Daun Kecombrang (Etlingera elatior) sebelum dan sesudah uji stabilitas dipercepat selama 5 siklus menggunakan alat climatic chamber.

\begin{tabular}{|c|c|c|c|c|c|c|}
\hline \multirow[b]{3}{*}{ NO } & \multirow[b]{3}{*}{ Formula } & \multicolumn{4}{|c|}{ Uji Mikroba Patogen } & \multirow{2}{*}{ Persyaratan } \\
\hline & & \multicolumn{2}{|c|}{ Sebelum pengujian } & \multicolumn{2}{|c|}{ Sesudah pengujian } & \\
\hline & & $\begin{array}{c}\text { Staphylococcus } \\
\text { aureus }\end{array}$ & $\begin{array}{c}\text { Pseudomonas } \\
\text { aeroginosa }\end{array}$ & $\begin{array}{c}\text { Staphylococcus } \\
\text { aureus }\end{array}$ & $\begin{array}{l}\text { Pseudomonas } \\
\text { aeroginosa }\end{array}$ & \multirow{3}{*}{$\begin{array}{c}\text { Staphylococcus } \\
\text { aureus dan } \\
\text { Pseudomonas } \\
\text { aeroginosa } \\
\text { negatif }\end{array}$} \\
\hline 1. & $\begin{array}{c}\text { Formula } 1 \\
(\text { Ekstrak 6,25\%) }\end{array}$ & Negatif & Negatif & Negatif & Negatif & \\
\hline 2. & $\begin{array}{c}\text { Formula } 2 \\
(\text { Ekstrak } 8,75 \%)\end{array}$ & Negatif & Negatif & Negatif & Negatif & \\
\hline
\end{tabular}


Tabel 7. Hasil Pengamatan Uji Aktivitas Sabun Cair Ekstrak Daun Kecombrang (Etlingera elatior) Terhadap Pertumbuhan Candida albicans sebelum uji stabilitas dipercepat selama 5 siklus menggunakan alat climatic chamber.

\begin{tabular}{cccccccccc}
\hline & & \multicolumn{4}{c}{ Uji Aktivitas (Diameter Zona Hambat mm) } \\
\cline { 3 - 9 } No. & Formula & \multicolumn{4}{c}{ Sebelum Pengujian } & \multicolumn{3}{c}{ Setelah Pengujian } \\
\cline { 3 - 9 } & I & II & III & Rata-Rata & I & II & III & Rata-Rata \\
\hline Formula 1 & 24 & 26 & 25 & 25,00 & 20 & 21 & 21 & 20,67 \\
\hline 1. & $\begin{array}{c}\text { Formula 2 } \\
\text { Fortrak 6,25\%) }\end{array}$ & 28 & 28 & 29 & 28,33 & 22 & 22 & 22 & 22,00 \\
\hline 3. & Bastrak 8,75\%) & 22 & 23 & 22 & 22,33 & 20 & 21 & 20 & 20,33 \\
\hline
\end{tabular}

\section{PEMBAHASAN}

Tujuan penelitian ini adalah untuk memformulasi sediaan sabun cair dari ekstrak Daun Kecombrang (Etlingera elatior), mengetahui kestabilan mutu fisik dan cemaran mikroorganimse dari sediaan sabun cair yang mengandung ekstrak Daun Kecombrang serta menentukan aktivitas sediaan sabun cair sebagai anti keputihan berdasarkan pengukuran zona hambat.

Ekstrak Daun Kecombrang diperoleh dengan cara mengekstraksi Daun Kecombrang yang sudah berupa simplisia kemudian diekstraksi dengan metode maserasi. Maserasi merupakan metode ekstraksi secara dingin yang digunakan untuk simplisia yang memiliki tekstur lunak seperti daun dan mengandung senyawa kimia yang rusak dengan pemanasan. Proses ekstraksinya dengan cara merendam simplisia dengan pelarut organik di dalam bejana maserator selama 5 hari dan sesekali diaduk. Selanjutnya diserkai, ekstrak yang diperoleh ditampung. Proses maserasi diulang sampai seluruh senyawa kimia terekstraksi dimana pelarut sudah tidak berwarna lagi atau jika dilakukan Kromatografi Lapis Tipis (KLT) tidak terdapat noda. Ekstrak cair yang diperoleh kemudian diuapkan dengan menggunakan evaporator dan dilanjutkan dengan waterbath. Tahap selanjutnya adalah formulasi sediaan sabun cair ekstrak Daun Kecombrang konsentrasi $6,25 \%$ dan $8,75 \%$, berdasarkan nilai Minimum Inhibition Concentration (MIC) terhadap pertumbuhan Candida albicans dan nilai Minimal Killing Concentration (MKC). Selanjutnya basis yang digunakan terdiri dari natrium lauril sulfat sebagai pembusa, gliserol sebagai pelembut, propilenglikol digunakan sebagai pembasah untuk mensuspensi ekstrak. Untuk memperoleh konsistensi yang bagus maka digunakan carbopol sebagai pengental dan untuk menghindari tumbuhnya mikroorganisme maka ditambahkan metil paraben sebagai pengawet. Serta ditambahkan pengaroma sehingga dihasilkan sediaan yang memiliki aroma yang khas. Langkah terakhir adalah mencukupkan volume sediaan dengan aquadest.

Selanjutnya dilakukan pengujian untuk mengevaluasi sediaan sesuai dengan syarat Standar Nasional Indonesia (SNI). Pengujian stabilitas dengan penyimpanan dipercepat menggunakan climatic chamber. Climatic chamber merupakan alat yang digunakan untuk pengujian stabilitas dipercepat dengan metode freeze thaw yaitu dengan menempatkan sediaan sabun cair pada suhu dingin sekitar $5^{\circ} \mathrm{C}$ selama 4 jam, kemudian sediaan dipindahkan lagi pada suhu sekitar $35^{\circ} \mathrm{C}$ selama 4 jam sebanyak 5 siklus. Evaluasi meliputi uji mutu fisik yang terdiri dari uji organoleptik, ketahanan busa dan uji pH. Uji organoleptik meliputi bentuk, warna dan bau. Uji ketahanan busa dilakukan untuk mengetahui kemampuan sediaan menghasilkan busa pada saat digunakan yang berfungsi untuk membersihkan kotoran. Uji pH untuk mengetahui keamanan sediaan. Hasil uji organoleptik untuk formula dengan konsentrasi ekstrak 6,25\% dan 8,75\% berupa bentuk, warna dan bau adalah sama ( tabel 1.). Hal ini menunjukkan variasi konsentrasi ekstrak tidak berpengaruh pada warna, bau dan bentuk formula. Uji ketahanan busa untuk kedua formula memenuhi syarat yaitu busa dapat bertahan lebih dari $60-70 \%$ setelah dikocok selama 5 menit (Tabel 2.)Untuk uji $\mathrm{pH}$ memenuhi syarat yaitu antara $3,8-4,5$ sesuai dengan $\mathrm{pH}$ vagina (Tabel 3 .). Hasil uji mutu fisik ini memenuhi syarat. Untuk mengetahui cemaran mikroorganisme 
yang dapat berasal dari kontaminasi bahan dan wadah yang digunakan serta kontaminasi selama proses formulasi maka dilakukan uji cemaran mikroorganisme yang terdiri dari Angka lempeng Total (ALT) bakteri, Angka Kapang Khamir (AKK) dan uji bakteri pathogen yaitu Pseudomonas aeroginosa dan Staphylococcus aureus. ALT bakteri dan AKK sebelum dan setelah penyimpanan dipercepat masing-masing diperoleh hasil < $10 \mathrm{koloni} / \mathrm{ml}$ yang memenuhi SNI BPOM yaitu maksimal $10 \mathrm{koloni} / \mathrm{ml}$ dan $<10$ koloni/ml yang memenuhi SNI BPOM yaitu maksimal 10 koloni/ml (Tabel 4.). Selanjutnya dilakukan uji identifikasi bakteri pathogen diperoleh hasil sebelum dan setelah pengujian dipercepat adalah Pseudomonas aeroginosa dan Staphylococcus aureus negative yang sesuai dengan SNI BPOM.

Pengujian selanjutnya adalah uji aktivitas terhadap Candida albicans. Untuk mengetahui perbedaan hasil uji aktivitas sebelum dan setelah penyimpanan dipercepat dilakukan uji statistik paired sampel T test. Hasil yang diperoleh menunjukkan bahwa aktivitas antikeputihan ekstrak Daun Kecombrang formula 6,25 \% terdapat perbedaan nyata antara pengujian sebelum dan setelah penyimpanan dipercepat. Begitupula dengan formula yang mengandung ekstrak Daun Kecombrang konsentrasi 8,75\%. Berdasarkan data yang diperoleh dapat dinyatakan adanya penurunan aktivitas sebelum dan setelah penyimpanan dipercepat. Hal ini disebabkan karena sediaan sudah mengalami perlakuan ekstrim selama penyimpanan dipercepat menggunakan climatic chamber, tetapi pada dasarnya sediaan masih memiliki aktivitas sebagai anti keputihan meskipun tidak sebesar sebelum penyimpanan. Untuk mengetahui perbedaan aktivitas antara sediaan $6,25 \%$ dan $8,75 \%$ sebelum penyimpanan dipercepat dilakukan uji normalitas dan uji homogenitas, diperoleh hasil uji normalitas tidak normal dan uji homogenitas diperoleh hasil homogen. Selanjutnya dilakukan uji non parametrik yaitu Kruskal-Wallis Test untuk melihat adanya perbedaan antar perlakuan dan diperoleh hasil ada perbedaan nyata. Untuk menentukan perbedaan antar kedua perlakuan maka dilakukan Mann-Whitney Test dengan hasil terdapat perbedaan yang bermakna antara sediaan dengan ekstrak 6,25
$\%$ dan $8,75 \%$, dimana aktivitas formula dengan ekstrak $8,75 \%$ lebih besar daripada $6,25 \%$. Hasil yang sama untuk pengujian setelah penyimpanan dipercepat.

Berdasarkan hasil pengujian yang diperoleh, maka dapat disimpulkan bahwa Ekstrak Daun Kecombrang (Etlingera elatior) dapat diformulasi dalam bentuk sediaan sabun cair dengan variasi konsentrasi ekstrak $6,25 \%$ dan $8,75 \%$. Hasil pengujian kestabilan dipercepat, memenuhi persyaratan uji organoleptis, uji ketahanan busa dan uji pH. Hasil uji cemaran mikroorganisme juga memenuhi syarat SNI BPOM. Sediaan memiliki aktivitas sebagai anti keputihan, dimana sediaan sabun cair 8,75\% memiliki aktivitas yang lebih besar dari konsentrasi $6,25 \%$.

\section{KESIMPULAN}

Berdasarkan hasil pengujian yang diperoleh, disimpulka Ekstrak Daun Kecombrang (Etlingera elatior) dapat diformulasi dalam bentuk sediaan sabun cair dengan variasi konsentrasi ekstrak 6,25\% dan $8,75 \%$. Hasil pengujian kestabilan dipercepat, masing-masing konsentrasi memenuhi persyaratan uji organoleptis, uji ketahanan busa dan uji pH. Hasil uji cemaran mikroorganisme juga memenuhi syarat SNI BPOM. Sediaan sabun cair ekstrak Daun kecombrang memiliki aktivitas sebagai anti keputihan, dimana sediaan sabun cair 8,75\% memiliki aktivitas yang lebih besar dari konsentrasi $6,25 \%$.

DAFTAR PUSTAKA

Baeda Madjid, 2003, Mikologi Medik. Hassanuddin University Press. Makassar

Departemen Kesehatan Republik Indonesia., 1986, Sediaan Galenik, Direktorat Jenderal Pengawasan Obat dan Makanan, Jakarta.

Departemen Kesehatan Republik Indonesia., 1995, Farmakope Indonesia, Edisi IV, Direktorat Jenderal Pengawasan Obat dan Makanan, Jakarta

Departemen Kesehatan
Indonesia, 2007, Pemanfaatan
Tanaman
Kesehatan
Jakarta.

Departemen Kesehatan Republik Tanaman Obat Departemen Jakarta. 
Dwiatmini, K., et al. 2009. Induksi Mutasi Kecombrang (Etlingera elatior) Menggunakan Iradiasi Sinar Gamma. Journal Hortikultura. Vol. 19 No. 1. Hal: 1-5.

Hidayat dan Hutapea, 1991, Inventarisasi Tanaman Obat Indonesia, Balai Penelitian dan Pengembangan Departemen Kesehatan RI

Jaffar F. M., C. P.Osman,. N.H. Ismail, and K. Awang. 2007. Analysis of Essential oils of leaves, stems, flowers, and Rhizomes of Etlingera elatior (JACK) R.M. SMITH. The Malaysian Journal of Analytical Scienses.

Manuaba IBG, 2003, Penuntun Kepaniteraan Klinik Obstetri dan Ginekologi. $2^{\text {nd }}$ ed. ECG, Jakarta.

Manuaba, I.A.C., Manuaba, I.B.G., Manuaba I.B.G.F., 2009, Memahami Kesehatan Reproduksi Wanita, $2^{\text {nd }}$ ed. Ester M, Editor, ECG, Jakarta.

Muawanah, A., et al., 2012. Penggunaan Bunga Kecombrang (Etlingera elatior) dalam Proses Fermentasi Permen Jelly. Jurnal Valensi Vol. 2 No. 4, Mei 2012 (526-533). ISSN : $1978-8193$

Naufalin. R., 2005. Kajian Sifat Antimkiroba Ekstrak Bunga Kecombrang (Nicolaia speciosa Horan) terhadap berbagai mikroba Patogen dan Perusak Pangan. Disertasi. Pascasarjana Institut Pertanian Bogor.
Niemi, A., 2009. Culinary Application of Torch Ginger Etlingera elatior. Bulletin Heliconia Society International. Vol.15 No. 3, Hal 11.

Petrucci, R.H., 1966, General chimetry (Edisi ketiga), Mac Millan, Publishing Co, INC, New York

Salasa, A.,M., Ratnah, S., Ibrahim, I., 2018, Penentuan Nilai MIC (Minimum Inhibitory Concentration) dan $\mathrm{MKC}$ (Minimum Killing Concentration) Ekstrak Daun Kecombrang Terhadap Candida albicans Penyebab Keputihan, Jurnal, Jurusan Farmasi Poltekkes Kemenkes Makassar, Makassar.

Sibagariang, E.E., Pusmaka, R., Rismalinda, 2010, Kesehatan Reproduksi Wanita, Trans Info Media, Jakarta.

Sirait. N., 2008. Penggunaan Berbagai Jenis tanaman Obat untuk menanggulangi Bau Badan. Journal WARTA Penelitian dan Pengembangan Tanaman Industri Vol. 14 (3) Hal: 89.

Tampubolon, O.T., S. Suhatsyah dan S.Sastrapradja. 1983. Penelitian Pendahuluan Kandungan Kimia Kecombrang (Nicolaia Speciosa Horan) dalam Risalah Simposium Penelitian Tumbuhan Obat III. Fakultas Farmasi UGM. DIY. Hal: 451-454. 